\title{
Establishment of Simple Nomograms for Predicting Axillary Lymph Node Involvement in Early Breast Cancer
}

This article was published in the following Dove Press journal: Cancer Management and Research

\author{
Qingqing Zong ${ }^{1, *}$ \\ Jing Deng ${ }^{1, *}$ \\ Wanli $\mathrm{Ge}^{2, *}$ \\ Jie Chen $\mathbb{D}^{\prime}$ \\ $\mathrm{Di} \mathrm{Xu}^{3}$
}

\begin{abstract}
'Department of Ultrasonography, The First Affiliated Hospital of Nanjing Medical University, Nanjing 210029, People's Republic of China; ${ }^{2}$ Department of General Surgery, The First Affiliated Hospital of Nanjing Medical University, Nanjing 210029, People's Republic of China; ${ }^{3}$ Department of Geriatric Medicine, The First Affiliated Hospital of Nanjing Medical University, Nanjing 210029, People's Republic of China
\end{abstract}

*These authors contributed equally to this work
Correspondence: $\mathrm{Di} \mathrm{Xu}$

Department of Geriatric Medicine, The

First Affiliated Hospital of Nanjing Medical

University, Nanjing 210029, People's

Republic of China

$\mathrm{Tel} / \mathrm{Fax}+8625837$ I 45II

Email I395I805973@I26.com
Purpose: Axillary lymph node (ALN) involvement is an important prognostic factor of early invasive breast cancer. The objective of this study was to establish simple nomograms for predicting ALN involvement based on ultrasound (US) characteristics and evaluate the predictive value of US in the detection of ALN involvement.

Patients and Methods: A total of 1328 patients with cT1-2N0 breast cancer by physical exam were retrospectively analyzed. Univariate analysis was used for the comparison of variables, and multivariate analysis was performed by binary logistic regression analysis. The $\mathrm{R}$ software was used to establish simple nomograms based on the US characteristics alone. The receiver operating characteristic (ROC) curves of the prediction model and the verification group were drawn, and the area under the curve (AUC) was calculated to evaluate the discrimination of the prediction model. A calibration curve was plotted to assess the nomogram predictions vs the actual observations of the ALN metastasis rate and axillary tumor burden rate.

Results: The ALN metastasis rates of the training group and the validation group were $35.1 \%$ and $34.1 \%$, respectively. Multivariate analysis showed that molecular subtype, lymphovascular invasion, mass descriptors (size, margin, microcalcification and blood flow signal) and LN descriptors (shape, cortical thickness and long-to-short ratio) were independent impact factors in early breast cancer. The AUC of ALN metastasis rate of prediction model based on US features was 0.802 , the AUC of high tumor burden rate was 0.873 , and the AUC of external validation group was 0.731 and 0.802 , respectively. The calibration curve of the nomogram showed that the nomogram predictions are consistent with the actual metastasis rate and the high tumor burden rate. The results showed that preoperative US had a sensitivity of $59.4 \%$ and a specificity of $88.9 \%$ for predicting the ALN metastasis rate.

Conclusion: The successfully established nomograms based on US characteristics to predict ALN metastasis rate and high axillary tumor burden rate in early breast cancer can achieve individual prediction. Compared with other nomogram predictions, it is more intuitive, and can help clinical decision-making; thus, it should be promoted. However, at this time US features alone are insufficient to replace sentinel lymph node biopsy.

Keywords: axillary lymph node involvement, early breast cancer, ultrasound, nomogram

\section{Introduction}

Axillary lymph node (ALN) involvement is associated with an increased risk of local recurrence and poor prognosis in early breast cancer. Accurate nodal $(\mathrm{N})$ staging is an important basis for the prognosis and adjuvant treatment of breast cancer. The main methods of $\mathrm{N}$ staging are sentinel lymph node biopsy (SLNB) and 
axillary lymph node dissection (ALND). Although ALND can clearly reveal the pathological $\mathrm{N}$ staging, it may also lead to serious complications such as edema and functional limitations of the affected upper limb, which seriously affect patients' quality of life. The 10-year follow-up results of the American College of Surgeons Oncology Group (ACOSOG) Z0011 trial showed that there was no statistically significant difference in the local recurrence rate and 10-year overall survival between the ALND group and the non-ALND group in early breast cancer with 1 or 2 SLNs containing metastases. ${ }^{1}$ With the emergence of systemic therapy and more accurate preoperative imaging diagnosis, individualized therapy has become an ideal choice for breast cancer treatment. ${ }^{2}$ The preoperative individualized noninvasive assessment of ALN involvement has received much attention from clinicians.

The Memorial Sloan-Kettering Cancer Center (MSKCC) model based on clinical and pathological features has been verified by large samples, ${ }^{3-5}$ but the nomogram for predicting axillary tumor burden based on ultrasound (US) features alone for early breast cancer has not been reported in the Chinese population. The establishment of a scoring system of axillary tumor burden for early breast cancer based on US characteristics alone will help predict individual axillary involvement and facilitate clinical decision-making. The purpose of this study was to establish a simple prediction model of ALN involvement in early breast cancer patients based on US characteristics and to evaluate its accuracy and the predictive value of US in the detection of ALN involvement.

\section{Patients and Methods}

\section{Patients}

In this study, 847 early breast cancer patients (cT1-2 and no enlarged ALNs by physical examination) who were diagnosed at the First Affiliated Hospital of Nanjing Medical University from 2017 to 2018 were included in a primary cohort, and 481 patients diagnosed in 2019 were included in a validation cohort. Patients were excluded from the study if they had a history of malignancy, immune system and hematological diseases or had received neoadjuvant chemotherapy or underwent surgery in the ipsilateral axillae. This retrospective study was conducted in accordance with the ethical standards of Declaration of Helsinki and was approved by the ethics committee of the First Affiliated Hospital of Nanjing Medical University. The requirement for informed consent was waived because this study does not adversely affect the rights and health of the participants, and the risk to the participants is not greater than the minimal risk. Patients' privacy and personally identifiable information are protected.

\section{US Examination}

All enrolled patients underwent preoperative US to assess the morphological features of LN using the MyLab twice (Esaote, Italian) and ACUSON S3000 (SIEMENS, Germany) systems, with a high-frequency transducer (10 to $18 \mathrm{MHz}$ ). The sonography was performed in accordance with the breast examination specification, and the instrument's frequency, focus, gain, and depth were adjusted appropriately to obtain the best image. The patient was in the supine position or lateral position, and the axillary was fully exposed by upper limb abduction. The bilateral axillae were comprehensively examined in multiple aspects, with a focus on ALNs in the I region (lateral to the pectoralis minor muscle). If suspicious ALNs were found on US, the inner mammary region and supraclavicular region were examined simultaneously. All enrolled patients were examined by a physician with at least 5 years of experience in breast US. The clinical and pathological data of enrolled patients were obtained from the medical records.

\section{US Evaluation}

The US features of the masses were evaluated and recorded according to the 5th edition of the Breast Imaging Reporting and Data System (BI-RADS) sonographic guidance, and the blood flow signals of the lesions were semiquantitatively graded by Adler and divided into 0, I, II, and III levels. ${ }^{6}$ In this study, level 0 -I was defined as poor blood flow, and level II-III was defined as abundant blood flow. The US characteristics of the ALNs were recorded in detail, including the shape, long-to-short ratio (LSR), maximum cortical thickness and blood flow. If there were suspicious ALNs on US, the number $(0,1,2$ or $>2)$ was recorded in detail. The parameters of suspicious ALNs indicated on US were as follows: cortical thickening $\geq 3 \mathrm{~mm}$ was taken as the main criterion, and asymmetric cortex, LSR $<2$, disappearance of hilum or abundant blood flow was taken as the second criterion. ${ }^{7,8}$ ALNs on US that met any of these criteria were characterized as suspicious for metastases.

\section{Pathological Evaluation}

After the size of all the surgical specimens of early breast cancer was recorded, routine HE staining and immunohistochemical (IHC) examination were performed. The IHC tests 
included estrogen receptor (ER), progesterone receptor (PR), human epidermal growth factor receptor-2 (Her2) amplification, and Ki67 proliferation index. The histological grade was divided into grade I, grade II and grade III. IHC diagnosis was referred to the breast cancer hormone receptor IHC testing guidelines and Her2 testing guidelines jointly issued by the American Society of Clinical Oncology/College Of American Pathologists guideline recommendations. ${ }^{9,10}$ There is no unified standard for the expression level of the Ki67 index. In this study, $\mathrm{Ki} 67<20 \%$ was regarded as low expression, and $\mathrm{Ki} 67 \geq 20 \%$ was regarded as high expression. The molecular subtype was divided into luminal A-like, luminal B-like, Her2 positive, and triple-negative breast cancer (TNBC). Axillary tumor burden was divided into low tumor burden (0 or 1-2 ALNs involving metastasis) and high tumor burden ( $>2$ ALNs involving metastasis).

\section{Statistical Analysis}

SPSS 22.0 software (IBM, Ehningen, Germany) was used for analysis. In univariate analysis, the chi-square test was used for the comparison of categorical variables, and $t$ test was used for the comparison of continuous variables. Binary logistic regression analysis was used for the multivariate analysis to determine related independent factors of clinicopathological and US characteristics. The rms package for $\mathrm{R}$ software (Windows version 3.6.1, https:/www.r-project. org) was used to establish a simple nomogram based on the US characteristics alone. Then, a validation group was used for external verification. The receiver operating characteristic (ROC) curves of the prediction model and the verification group were drawn, and the area under the curve (AUC) was calculated to evaluate the discrimination of the prediction model. A calibration curve was plotted to assess the nomogram predictions vs the actual observations of the ALN metastasis rate and axillary tumor burden rate. $\mathrm{P}<0.05$ was considered statistically significant.

\section{Results}

\section{Clinicopathological Characteristics}

The mean age of the 1328 enrolled patients was 53.36 \pm 11.67 years, while the mean ages of the training group and the validation group were $55.53 \pm 11.82$ and 53.08 \pm 11.41 years, respectively. Of all patients, there were 1192 (89.8\%) with invasive ductal carcinoma (IDC), 36 $(2.7 \%)$ with invasive lobular carcinoma (ILC) and 100 (7.5\%) with other types. The ALN metastasis rates of the training group and the validation group were $35.1 \%$ and
$34.1 \%$, respectively, with no significant difference in the distribution between the two groups. The distribution of variables in the validation group was basically the same as that in the training group, with slight differences among the eight variables, including histological grade, Her2 status, Ki67 index, axillary surgery, mass aspect ratio, mass microcalcification, LN shape and blood flow (Table 1).

\section{Predictors of ALN Involvement}

Univariate analysis showed that histological grade, ER status, Ki67 index, molecular subtype, lymphovascular invasion (LVI), mass descriptors (size, margin, microcalcification and blood flow signal) and LN descriptors (shape, cortical thickness, LSR and blood flow signal) had statistical significance for ALN involvement in early breast cancer. However, age, histological type, PR status, Her2 status and mass aspect ratio were not statistically significant $(\mathrm{P}>0.05)$ (Table 2).

Binary logistic regression analysis was performed for the axillary metastasis of early breast cancer based on clinicopathological combined with US features and based on US features alone. The results showed that molecular subtype, LVI, mass descriptors (size, margin, microcalcification and blood flow signal) and LN descriptors (shape, cortical thickness and LSR) are independent impact factors of ALN metastasis in early breast cancer; LVI, mass descriptors (size and microcalcification) and LN descriptors (shape, cortical thickness and LSR) were independent influence factors of axillary tumor burden in early breast cancer (Table 3). Cortical thickness of $\mathrm{LN}$ had a higher risk of ALN metastasis (OR 4.363; 95\% CI, 2.629-7.242) and axillary tumor burden (OR 5.865; 95\% CI, 3.035-11.336) in the training group.

\section{Establishment and Evaluation of Nomograms}

The ROC curves of the training group and the validation group were drawn based on the clinicopathological features combined with the US features and based on the US features alone. The AUC of the ALN metastasis rate based on the US features alone in the training group was 0.802 (95\% CI, 0.770-0.834), and the AUC in the validation group was $0.731(95 \% \mathrm{CI}, 0.680-0.781)$. The AUC of high axillary tumor burden rate based on the US features alone in the training group was 0.873 (95\% CI, 0.836-0.910 ), and the AUC in the validation group was 0.802 (95\% CI, 0.740-0.865) (Figure 1).

The prediction model of ALN metastasis rate based on US characteristics had a predictive accuracy of $76.9 \%$, 
Table I Clinicopathological and US Features of the Training Group and Validation Group in Early Breast Cancer

\begin{tabular}{|c|c|c|c|c|}
\hline Variables & Training Group $(n=847)$ & Validation Group $(n=48 I)$ & Total $(n=1328)$ & $\mathbf{P}$ \\
\hline \multicolumn{5}{|l|}{ Age (year) } \\
\hline Average (SD) & $55.53(\mid 11.82)$ & $53.08(\mid I .4 I)$ & $53.36(11.67)$ & 0.392 \\
\hline Range & $25-92$ & $23-91$ & $23-92$ & \\
\hline Pathological type & & & & 0.568 \\
\hline IDC & $762(90.0)$ & $430(89.4)$ & $1192(89.8)$ & \\
\hline ILC & $20(2.4)$ & $16(3.3)$ & $36(2.7)$ & \\
\hline Others & $65(7.7)$ & $35(7.3)$ & $100(7.5)$ & \\
\hline \multicolumn{5}{|l|}{ Histological grade } \\
\hline 1 & $31(3.7)$ & $10(2.1)$ & $4 I(3.1)$ & 0.000 \\
\hline II & $453(53.5)$ & $216(44.9)$ & $669(50.4)$ & \\
\hline III & $302(35.7)$ & $234(48.6)$ & $536(40.4)$ & \\
\hline Unknown & $61(7.2)$ & $21(4.4)$ & $82(6.2)$ & \\
\hline ER & & & & 0.295 \\
\hline$(-)$ & $223(26.3)$ & $114(23.7)$ & $337(25.4)$ & \\
\hline$(+)$ & $624(73.7)$ & $367(76.3)$ & $991(74.6)$ & \\
\hline PR & & & & 0.635 \\
\hline$(-)$ & $303(35.8)$ & $179(37.2)$ & $482(36.3)$ & \\
\hline$(+)$ & $544(64.2)$ & $302(62.8)$ & $846(63.7)$ & \\
\hline Her2 & & & & 0.031 \\
\hline$(-)$ & $649(76.6)$ & $393(81.7)$ & $1042(78.5)$ & \\
\hline$(+)$ & $198(23.4)$ & $88(18.3)$ & $286(21.5)$ & \\
\hline Ki-67 & & & & 0.013 \\
\hline Low & $179(2 \mid .1)$ & $|3|(27.2)$ & $310(23.3)$ & \\
\hline High & 668(78.9) & $350(72.8)$ & $1018(76.7)$ & \\
\hline Molecular subtype & & & & 0.127 \\
\hline Luminal A-like & $156(18.4)$ & $88(18.3)$ & $244(18.4)$ & \\
\hline Luminal B-like & $47 \mid(55.6)$ & $279(58.0)$ & $750(56.5)$ & \\
\hline Her2 positive & $101(11.9)$ & $38(7.9)$ & $139(10.5)$ & \\
\hline TNBC & $119(14.0)$ & $76(15.8)$ & $195(14.7)$ & \\
\hline LVI & & & & 0.423 \\
\hline No & 693(81.8) & $385(80.0)$ & $1078(8 \mid .2)$ & \\
\hline Yes & $154(18.2)$ & $96(20.0)$ & $250(18.8)$ & \\
\hline Surgery & & & & 0.000 \\
\hline ALND alone & $297(35.1)$ & $124(25.8)$ & $421(31.7)$ & \\
\hline SLNB alone & $4 I I(48.5)$ & $292(60.7)$ & $703(52.9)$ & \\
\hline SLNB+ALND & $139(16.4)$ & $65(13.5)$ & $204(15.4)$ & \\
\hline ALN involvement & & & & 0.823 \\
\hline 0 & $550(64.9)$ & $317(65.9)$ & $867(65.3)$ & \\
\hline $\mathrm{I}-2$ & 194(22.9) & $1 I I(23.1)$ & $305(23.0)$ & \\
\hline$>2$ & $103(12.2)$ & $53(11.0)$ & $156(11.7)$ & \\
\hline Mass size $(\mathrm{cm})$ & & & & 0.249 \\
\hline Average(SD) & $2.23(0.93)$ & $2.23(0.89)$ & $2.22(0.91)$ & \\
\hline Range & $0.2-5.0$ & $0.5-4.9$ & $0.2-5.0$ & \\
\hline Mass shape & & & & 0.422 \\
\hline
\end{tabular}

(Continued) 
Table I (Continued).

\begin{tabular}{|c|c|c|c|c|}
\hline Variables & Training Group $(n=847)$ & Validation Group $(n=48 I)$ & Total $(n=1328)$ & $\mathbf{P}$ \\
\hline Irregular & 207(24.) & $108(22.5)$ & $315(23.7)$ & \\
\hline Regular & $640(75.6)$ & $373(77.5)$ & $1013(76.3)$ & \\
\hline Mass margin & & & & 0.387 \\
\hline Smooth & $170(20.1)$ & $87(18.1)$ & $257(19.4)$ & \\
\hline Obscure & $677(79.9)$ & $394(81.9)$ & $107 \mid(80.6)$ & \\
\hline Mass aspect ratio & & & & 0.000 \\
\hline$<1$ & $435(5 I .4)$ & $307(63.8)$ & $742(55.9)$ & \\
\hline$\geq 1$ & $412(48.6)$ & $174(36.2)$ & $586(44.1)$ & \\
\hline Mass microcalcification & & & & 0.002 \\
\hline No & $373(44.0)$ & $255(53.0)$ & $628(47.3)$ & \\
\hline Yes & $474(56.0)$ & $226(47.0)$ & $700(52.7)$ & \\
\hline Mass blood & & & & 0.293 \\
\hline Poor & $170(20.1)$ & $109(22.7)$ & $279(21.0)$ & \\
\hline Abundant & $677(79.9)$ & $372(77.3)$ & $1049(79.0)$ & \\
\hline LN shape & & & & 0.022 \\
\hline Absence of hilum & $54(6.4)$ & $34(7.1)$ & $88(6.6)$ & \\
\hline Symmetrical cortex & $618(73.0)$ & $377(78.4)$ & $995(74.9)$ & \\
\hline Asymmetrical cortex & $175(20.7)$ & $70(14.6)$ & $245(18.5)$ & \\
\hline LN cortical thickness $(\mathrm{mm})$ & & & & 0.078 \\
\hline Average(SD) & $2.27(1.72)$ & $2.11(1.40)$ & $2.21(1.6 I)$ & \\
\hline Range & $0.5-12$ & $0.6-10$ & $0.5-12$ & \\
\hline LN LSR & & & & 0.096 \\
\hline$\geq 2$ & $706(83.4)$ & $418(86.9)$ & II $24(84.6)$ & \\
\hline$<2$ & $|4|(\mid 6.6)$ & $63(13.1)$ & $204(15.4)$ & \\
\hline LN blood & & & & 0.011 \\
\hline Poor & $652(77.0)$ & $399(83.0)$ & $105 \mid(79.1)$ & \\
\hline Abundant & $195(23.0)$ & $82(17.0)$ & $277(20.9)$ & \\
\hline No. of abnormal LN on US & & & & 0.691 \\
\hline 0 & $593(70.0)$ & $347(72.1)$ & $940(70.8)$ & \\
\hline $\mathrm{I}-2$ & $173(20.4)$ & $93(19.3)$ & $266(20.0)$ & \\
\hline$>2$ & $81(9.6)$ & $4 I(8.5)$ & $122(9.2)$ & \\
\hline
\end{tabular}

negative predictive value (NPV) of $78.3 \%$, positive predictive value (PPV) of $72.9 \%$, and a test value of $75.9 \%$ in the validation cohort. The prediction model of axillary tumor burden rate based on US characteristics had a predictive accuracy of $89.4 \%$, NPV of $90.4 \%$, PPV of $67.6 \%$, and a test value of $87.7 \%$ in the validation cohort. Based on the results of regression analysis, the independent predictors of the training group were integrated. Compared with the AUC values based on the clinicopathological features combined with the US features, the AUC value of the ROC curve did not decrease significantly in the prediction model with only US features.
$\mathrm{R}$ software was used to establish the nomograms for the prediction of the ALN metastasis rate and high axillary tumor burden rate in early breast cancer (Figure 2). The calibration curve of the nomogram showed that the nomogram predictions are consistent with the actual metastasis rate and the high tumor burden rate, indicating that the prediction accuracy of the nomogram of the prediction model is high (Figure 3).

\section{Distribution of Patients with Abnormal ALNs on US} Preoperative US had a sensitivity of 59.4\% and a specificity of $88.9 \%$ for predicting the ALN metastasis rate. Among women with $>2$ abnormal ALNs identified on preoperative 
Table 2 Univariate Analysis of ALN Involvement in the Training Group

\begin{tabular}{|c|c|c|c|c|}
\hline Variables & $\begin{array}{l}\text { LN- } \\
(n=550)\end{array}$ & $\begin{array}{l}L N+(I-2) \\
(n=194)\end{array}$ & $\begin{array}{l}\mathrm{LN}+(>2) \\
(n=103)\end{array}$ & $\mathbf{P}$ \\
\hline $\begin{array}{l}\text { Age (year) } \\
\text { Average(SD) } \\
\text { Range }\end{array}$ & $\begin{array}{l}53.98(\mid 1.76) \\
25-92\end{array}$ & $\begin{array}{l}53.14(11.58) \\
27-87\end{array}$ & $\begin{array}{l}51.86(12.46) \\
26-80\end{array}$ & 0.391 \\
\hline $\begin{array}{l}\text { Pathological type } \\
\text { IDC } \\
\text { ILC } \\
\text { Others }\end{array}$ & $\begin{array}{l}486(88.4) \\
13(2.4) \\
51(9.3)\end{array}$ & $\begin{array}{l}181(93.3) \\
3(1.5) \\
10(5.2)\end{array}$ & $\begin{array}{l}95(92.2) \\
4(3.9) \\
4(3.9)\end{array}$ & 0.117 \\
\hline $\begin{array}{l}\text { Histological grade } \\
\text { I } \\
\text { II } \\
\text { III } \\
\text { Unknown }\end{array}$ & $\begin{array}{l}28(5.1) \\
301(54.7) \\
171(31.1) \\
50(9.1)\end{array}$ & $\begin{array}{l}3(1.5) \\
102(52.6) \\
82(42.3) \\
7(3.6)\end{array}$ & $\begin{array}{l}0(0.0) \\
50(48.5) \\
49(47.6) \\
4(3.9)\end{array}$ & 0.000 \\
\hline $\begin{array}{l}\text { ER } \\
\qquad \begin{array}{l}(-) \\
(+)\end{array}\end{array}$ & $\begin{array}{l}156(28.4) \\
394(71.6)\end{array}$ & $\begin{array}{l}36(18.6) \\
158(81.4)\end{array}$ & $\begin{array}{l}31(30.1) \\
72(69.9)\end{array}$ & 0.019 \\
\hline $\begin{array}{l}\text { PR } \\
\qquad \begin{array}{l}(-) \\
(+)\end{array}\end{array}$ & $\begin{array}{l}209(38.0) \\
34 I(62.0)\end{array}$ & $\begin{array}{l}61(31.4) \\
133(68.6)\end{array}$ & $\begin{array}{l}33(32.0) \\
70(68.0)\end{array}$ & 0.183 \\
\hline $\begin{array}{r}\text { Her2 } \\
(-) \\
(+)\end{array}$ & $\begin{array}{l}426(77.5) \\
124(22.5)\end{array}$ & $\begin{array}{l}153(78.9) \\
41(21.1)\end{array}$ & $\begin{array}{l}70(68.0) \\
33(32.0)\end{array}$ & 0.079 \\
\hline $\begin{array}{l}\text { Ki-67 } \\
\text { Low } \\
\text { High }\end{array}$ & $\begin{array}{l}140(25.5) \\
410(74.5)\end{array}$ & $\begin{array}{l}32(16.5) \\
162(83.5)\end{array}$ & $\begin{array}{l}7(6.8) \\
96(93.2)\end{array}$ & 0.000 \\
\hline $\begin{array}{l}\text { Molecular subtype } \\
\text { Luminal A-like } \\
\text { Luminal B-like } \\
\text { Her2 positive } \\
\text { TNBC }\end{array}$ & $\begin{array}{l}119(21.6) \\
276(50.2) \\
65(11.8) \\
90(16.4)\end{array}$ & $\begin{array}{l}30(15.5) \\
128(66.0) \\
17(8.8) \\
19(9.8)\end{array}$ & $\begin{array}{l}7(6.8) \\
67(65.0) \\
19(18.4) \\
10(9.7)\end{array}$ & 0.001 \\
\hline $\begin{array}{l}\text { LVI } \\
\text { No } \\
\text { Yes }\end{array}$ & $\begin{array}{l}512(93.1) \\
38(6.9)\end{array}$ & $\begin{array}{l}133(68.6) \\
61(31.4)\end{array}$ & $\begin{array}{l}48(46.6) \\
55(53.4)\end{array}$ & 0.000 \\
\hline $\begin{array}{l}\text { Mass size }(\mathrm{cm}) \\
\leq 2 \\
>2\end{array}$ & $\begin{array}{l}296(53.8) \\
254(46.2)\end{array}$ & $\begin{array}{l}86(44.3) \\
108(55.7)\end{array}$ & $\begin{array}{l}25(24.3) \\
78(75.7)\end{array}$ & 0.000 \\
\hline $\begin{array}{l}\text { Mass shape } \\
\text { Irregular } \\
\text { Regular }\end{array}$ & $\begin{array}{l}148(26.9) \\
402(73.1)\end{array}$ & $\begin{array}{l}44(22.7) \\
150(77.3)\end{array}$ & $\begin{array}{l}15(14.6) \\
88(85.4)\end{array}$ & 0.023 \\
\hline $\begin{array}{l}\text { Mass margin } \\
\text { Smooth } \\
\text { Obscure }\end{array}$ & $\begin{array}{l}140(25.5) \\
410(74.5)\end{array}$ & $\begin{array}{l}22(11.3) \\
172(88.7)\end{array}$ & $\begin{array}{l}8(7.8) \\
95(92.2)\end{array}$ & 0.000 \\
\hline $\begin{array}{l}\text { Mass aspect ratio } \\
<1 \\
\geq 1\end{array}$ & $\begin{array}{l}285(51.8) \\
265(48.2)\end{array}$ & $\begin{array}{l}96(49.5) \\
98(50.5)\end{array}$ & $\begin{array}{l}54(52.4) \\
49(47.6)\end{array}$ & 0.833 \\
\hline
\end{tabular}

(Continued)
Table 2 (Continued).

\begin{tabular}{|c|c|c|c|c|}
\hline Variables & $\begin{array}{l}\mathrm{LN}- \\
(n=550)\end{array}$ & $\begin{array}{l}\mathrm{LN}+(1-2) \\
(n=194)\end{array}$ & $\begin{array}{l}\mathrm{LN}+(>2) \\
(n=103)\end{array}$ & $\mathbf{P}$ \\
\hline $\begin{array}{l}\text { Mass } \\
\text { microcalcification } \\
\text { No } \\
\text { Yes }\end{array}$ & $\begin{array}{l}269(48.9) \\
28 I(5 I . I)\end{array}$ & $\begin{array}{l}76(39.2) \\
118(60.8)\end{array}$ & $\begin{array}{l}28(27.2) \\
75(72.8)\end{array}$ & 0.000 \\
\hline $\begin{array}{l}\text { Mass blood } \\
\text { Poor } \\
\text { Abundant }\end{array}$ & $\begin{array}{l}108(19.6) \\
442(80.4)\end{array}$ & $\begin{array}{l}50(25.8) \\
144(74.2)\end{array}$ & $\begin{array}{l}12(11.7) \\
91(88.3)\end{array}$ & 0.014 \\
\hline $\begin{array}{l}\text { LN shape } \\
\text { Absence of hilum } \\
\text { Symmetrical } \\
\text { cortex } \\
\text { Asymmetrical } \\
\text { cortex }\end{array}$ & $\begin{array}{l}4(0.7) \\
474(86.2) \\
72(13.1)\end{array}$ & $\begin{array}{l}26(13.4) \\
113(58.2) \\
55(28.4)\end{array}$ & $\begin{array}{l}24(23.3) \\
32(30.1) \\
47(46.6)\end{array}$ & 0.000 \\
\hline $\begin{array}{l}\text { LN cortical } \\
\text { thickness }(\mathrm{mm}) \\
\quad<3 \\
\geq 3\end{array}$ & $\begin{array}{l}499(90.7) \\
51(9.3)\end{array}$ & $\begin{array}{l}119(61.3) \\
75(38.7)\end{array}$ & $\begin{array}{l}25(24.3) \\
78(75.7)\end{array}$ & 0.000 \\
\hline $\begin{array}{l}\text { LN LSR } \\
\quad \geq 2 \\
<2\end{array}$ & $\begin{array}{l}516(93.8) \\
34(6.2)\end{array}$ & $\begin{array}{l}|4|(72.7) \\
53(27.3)\end{array}$ & $\begin{array}{l}49(47.6) \\
54(52.4)\end{array}$ & 0.000 \\
\hline $\begin{array}{l}\text { LN blood } \\
\text { Poor } \\
\text { Abundant }\end{array}$ & $\begin{array}{l}48 \mid(87.5) \\
69(12.5)\end{array}$ & $\begin{array}{l}129(66.5) \\
65(33.5)\end{array}$ & $\begin{array}{l}42(40.8) \\
61(59.2)\end{array}$ & 0.000 \\
\hline
\end{tabular}

Abbreviations: $\mathrm{LN}-$, disease-free axillae; $\mathrm{LN}+$, any nodal metastasis; $\mathrm{LN}+(\mathrm{I}-2)$, I or 2 nodal metastasis; $\mathrm{LN}+(>2)$, more than 2 nodal metastasis.

US, $69.4 \%$ had $>2$ positive ALNs on final pathology. Among women without abnormal ALNs on preoperative US, $80.2 \%$ had negative ALNs on final pathology. Among patients with 1-2 abnormal ALNs on preoperative US, 94.2\% had 1-2 positive ALNs on final pathology (Figure 4).

\section{Discussion}

The choice of axillary surgery for early breast cancer has become increasingly controversial. With the improvement of imaging equipment and the diagnostic level, the traditional invasive method of $\mathrm{N}$ staging has been challenged. However, due to differences in patients' willingness and clinicians' preferences, the selection of appropriate surgical methods based on axillary imaging evaluation is still controversial.

The ACOSOG Z0011 trial showed that there was no significant difference in the 10-year overall survival between the SLNB group and ALND group of earlystage breast cancer patients with 1-2 positive SLNs. The 
Table 3 Logistic Regression Analysis of ALN Involvement in the Training Group

\begin{tabular}{|c|c|c|c|c|c|c|c|c|}
\hline \multirow[t]{3}{*}{ Variables } & \multicolumn{4}{|l|}{ LN- vs LN+ } & \multicolumn{4}{|c|}{$L N-$ and $L N+(1-2)$ vs $L N+(>2)$} \\
\hline & \multicolumn{2}{|c|}{$\begin{array}{l}\text { Clinicopathological and } \\
\text { US Features }\end{array}$} & \multicolumn{2}{|l|}{ US Features } & \multicolumn{2}{|c|}{$\begin{array}{l}\text { Clinicopathological and } \\
\text { US Features }\end{array}$} & \multicolumn{2}{|l|}{ US Features } \\
\hline & OR(95\% Cl) & $\mathbf{P}$ & OR(95\% Cl) & $\mathbf{P}$ & OR(95\% Cl) & $\mathbf{P}$ & OR(95\% Cl) & $\mathbf{P}$ \\
\hline Molecular subtype & $0.736(0.594-0.912)$ & 0.005 & - & - & - & - & - & - \\
\hline LVI & $6.755(4.248-10.74 I)$ & 0.000 & - & - & $4.799(2.837-8.117)$ & 0.000 & - & - \\
\hline Mass size & - & - & $1.522(1.080,2.145)$ & 0.016 & $2.757(1.557-4.882)$ & 0.001 & $2.619(1.527-4.492)$ & 0.000 \\
\hline Mass margin & $2.192(1.308-3.673)$ & 0.003 & $2.48 I(I .5 I 5,4.06 I)$ & 0.000 & - & - & - & - \\
\hline Mass microcalcification & $1.768(1.208-2.587)$ & 0.003 & $1.847(1.291-2.644)$ & 0.001 & $2.311(1.332-4.010)$ & 0.003 & $2.682(1.572-4.576)$ & 0.000 \\
\hline Mass blood & $0.58 \mid(0.369-0.917)$ & 0.020 & $0.559(0.362-0.862)$ & 0.008 & - & - & - & - \\
\hline LN cortical thickness & $4.195(2.425-7.256)$ & 0.000 & $4.363(2.629-7.242)$ & 0.000 & $5.439(2.735-10.818)$ & 0.000 & $5.865(3.035-11.336)$ & 0.010 \\
\hline LN shape & $1.585(1.212-2.073)$ & 0.001 & $1.428(1.116-1.827)$ & 0.005 & $1.546(1.091-2.190)$ & 0.014 & I.543(I.109-2.149) & 0.000 \\
\hline LN LSR & $4.038(2.391-6.819)$ & 0.000 & $4.216(2.587-6.873)$ & 0.000 & $3.181(1.811-5.587)$ & 0.000 & $3.614(2.090-6.248)$ & 0.000 \\
\hline
\end{tabular}

latest edition of the National Comprehensive Cancer Network (NCCN) guidelines suggests that ALND may be conditionally exempted in early breast cancer with positive SLNs. ${ }^{11}$ In the era of precision medicine, accurate preoperative $\mathrm{N}$ staging in early breast cancer is of great significance for the development of individualized treatment and the selection of appropriate surgical procedures. US plays an important role in the axillary evaluation of early breast cancer.

The predictive model based on clinicopathological and US features can screen out more patients with ALN metastasis, which is more in line with clinical research purposes. However, the prediction model based on US features alone used fewer variables, so it is easy to generalize. In this study, the nomogram based on US features was verified to be of high accuracy, and compared with the prediction model based on clinicopathological and US features, it is simpler and more intuitive. Moreover, it can realize the individualized prediction of the ALN metastasis rate and high axillary tumor burden rate and will become an important tool for the preoperative noninvasive evaluation of early breast cancer. The nomogram showed that early breast cancer with a higher rate of ALN metastasis had a luminal B-like subtype, a larger tumor size, an obscure margin, microcalcification and poor blood flow on masses, an asymmetric cortical thickness $\geq 3 \mathrm{~mm}$, LNs without hilum, and LSR $<2$. Early breast cancer patients with a larger tumor size, mass microcalcification, asymmetric cortical thickness $\geq 3 \mathrm{~mm}$ and $\mathrm{LSR}<2$ were more likely to have a higher axillary tumor burden.

Previous studies have shown that cortical thickness is the strongest predictor of ALN involvement. ${ }^{12}$ The results of this study showed that the cortical thickness and shape of ALNs were associated with a higher risk of ALN metastasis or a higher axillary tumor burden, which was basically consistent with the findings of previous studies. ${ }^{13,14}$ In this study, cortical thickness was not specifically graded but was only evaluated at the time of initial diagnosis. The results still showed that with increased cortical thickness, the higher the risk of ALN metastasis and the greater the risk of high tumor burden.

Guo et al suggested that the US features of irregular shape and higher color Doppler flow imaging grades of masses correlated well with ALN metastasis. ${ }^{15}$ However, we found that patients with poor blood flow in masses were more likely to have ALN metastasis by the simple nomogram. The differences in the results may stem from the differences in the enrolled populations. In addition, the obscure margin of the mass is also an important predictor of ALN metastasis, which is consistent with previous results. ${ }^{16,17}$ Zhang et al reported a multicenter study of 1869 female patients from seven Chinese breast cancer centers and showed that molecular subtype was an independent predictor of ALN metastasis. ${ }^{18,19}$ In this study, multivariate analysis showed a correlation between molecular subtype and ALN involvement in early breast cancer, which was consistent with the findings of previous studies. ${ }^{20}$ However, Xin et al found that there was no significant correlation between molecular subtype and ALN metastasis in 323 patients with newly diagnosed breast cancer and suggested that molecular subtype could not predict ALN involvement currently and could not fully reveal the biological characteristics of tumors. ${ }^{21}$

The nomograms based on US characteristics were successfully established to predict the ALN metastasis rate 

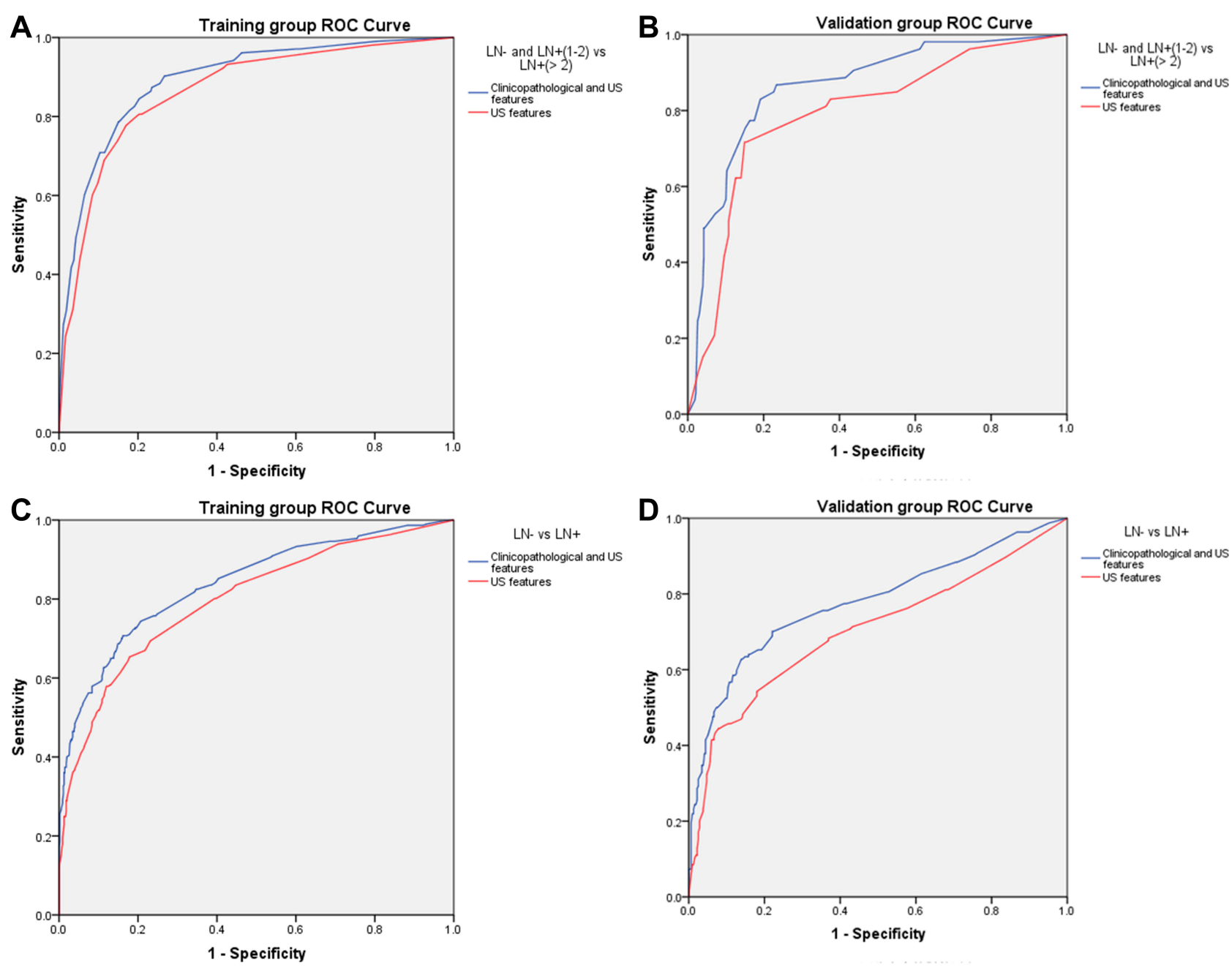

Figure I ROC curve of predictive model in early breast cancer

Notes: (A) ROC curve of predicting $L N-$ and $L N+(I-2)$ vs $L N+(>2)$ in the training group; (B) ROC curve of predicting $L N-$ and $L N+(I-2)$ vs $L N+(>2)$ in the validation group; (C) ROC curve of predicting $\mathrm{LN}-$ vs $\mathrm{LN}+$ in the training group; (D) ROC curve of predicting $\mathrm{LN}-$ vs $\mathrm{LN}+$ in the validation group.

Abbreviations: $\mathrm{LN}-$, disease-free axillae; $\mathrm{LN}+$, any nodal metastasis; $\mathrm{LN}+(\mathrm{I}-2)$, I or 2 nodal metastasis; $\mathrm{LN}+(>2)$, more than 2 nodal metastasis.

and high tumor burden rate; the AUC values verified externally in the validation group were 0.731 and 0.802 , respectively. The calibration curve of the nomogram shows that the nomogram prediction is consistent with the actual metastasis rate and the high tumor burden rate. The MSKCC model was established to predict the ALN metastasis rate, but it only considered clinicopathological features without adding imaging features. However, the nomogram in this study introduced US characteristics, which have wider clinical applicability and easier operation. The results of this study showed that through the simple prediction model, $79.0 \%$ of patients with negative ALNs could be screened out to avoid unnecessary axillary surgery, $91.1 \%$ of patients with a low axillary tumor burden could be screened out to avoid unnecessary ALND, and $62.7 \%$ of patients with a high tumor burden could be screened out to receive ALND directly to avoid injury from secondary surgery.

US is the most widely used assistive examination technique to evaluate ALN involvement. Comprehensive US may help accurately assess ALN involvement in early invasive breast cancer to guide clinical decision-making. In this study, 1204 patients with $\leq 2$ suspicious ALNs were screened by preoperative US, of which $94.2 \%$ were pathologically confirmed to have a low axillary tumor burden. The specificity of US for evaluating axillary tumor burden was high, and SLNB was preferred for patients with $\leq 2$ suspicious ALNs. Some patients can avoid unnecessary ALND, reduce surgical complications, and save medical resources such as rapid frozen sections during surgery. Among patients with negative US in early breast cancer, $19.8 \%$ had ALN metastasis in the axillae by postoperative 


A
Points
Mass size
$\begin{aligned} & \text { Mass } \\ & \text { microcalcification } \\ & \text { Mass margin }\end{aligned}$
Mass blood
LN cortex
LN shape
LNLSR
Total Points
Risk1
B

Points

Mass size

Mass

microcalcification

LN cortex

LN shape

LNLSR

Total Points

Risk2

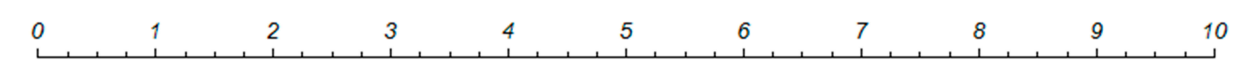
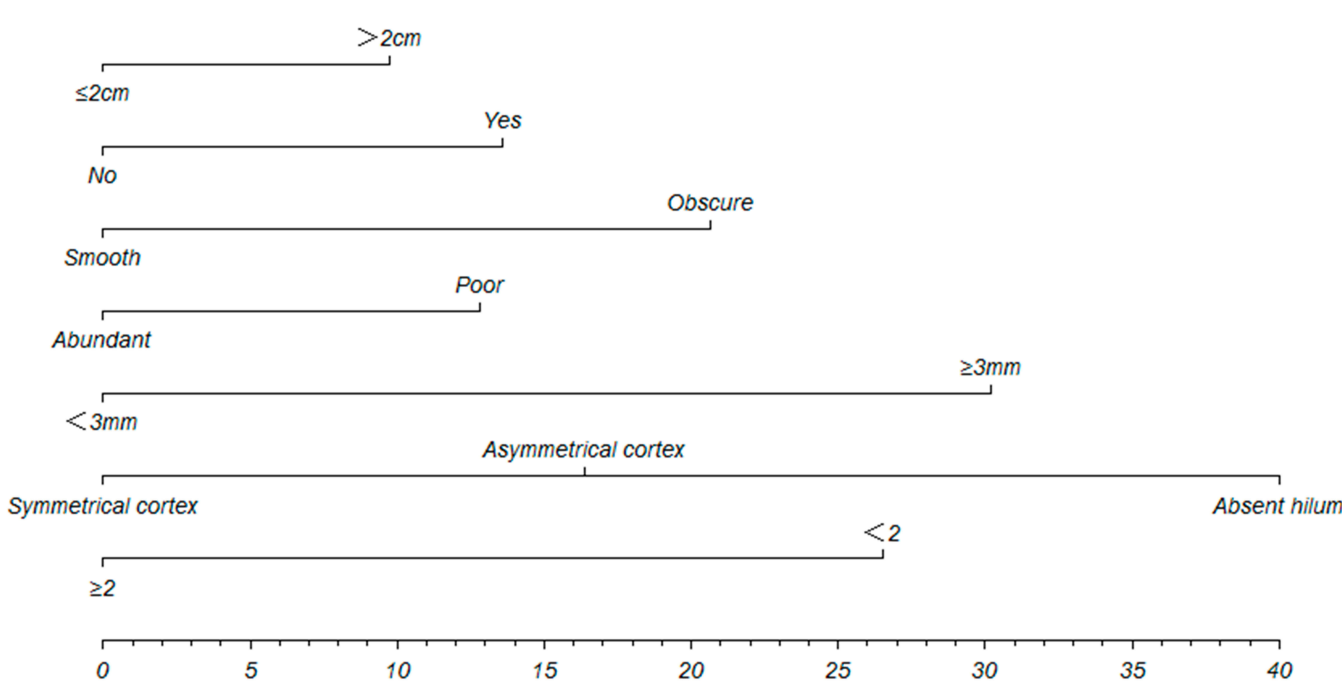

\begin{tabular}{lllllllll}
\hline 0.1 & 0.2 & 0.3 & 0.4 & 0.5 & 0.6 & 0.7 & 0.8 & 0.9
\end{tabular}

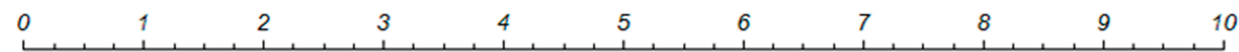
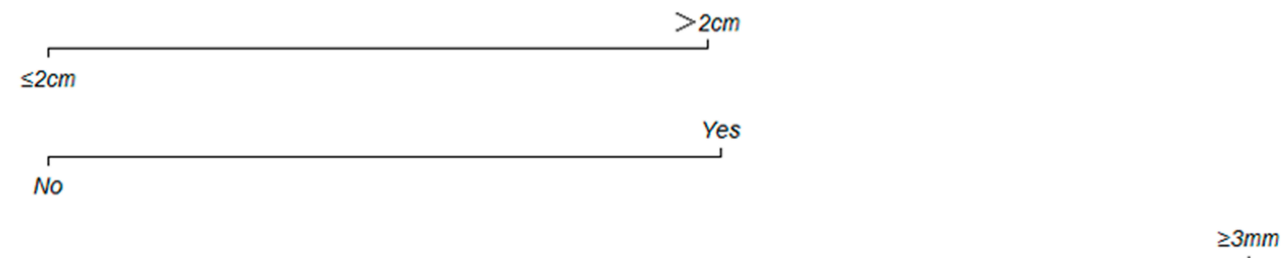

$$
<3 m m
$$

$\geq 3 \mathrm{~mm}$
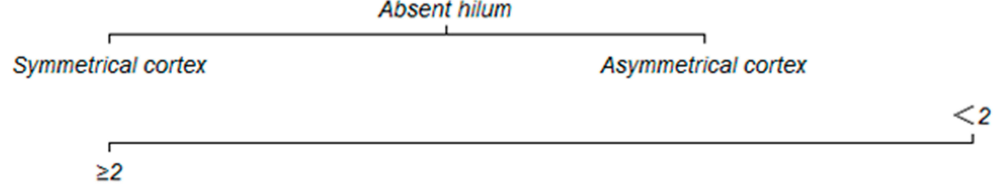

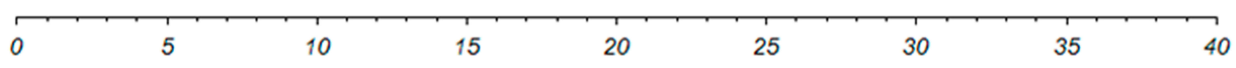

Figure 2 The nomograms of predictive model in early breast cancer

Notes: (A) the predictive model of Riskl ( $\mathrm{LN}-\mathrm{vs} \mathrm{LN}+)$; (B) the predictive model of Risk2 ( $\mathrm{LN}-$ and $\mathrm{LN}+(\mathrm{I}-2)$ vs $\mathrm{LN}+(>2))$.

Abbreviations: $\mathrm{LN}-$, disease-free axillae; $\mathrm{LN}+$, any nodal metastasis; $\mathrm{LN}+(\mathrm{I}-2)$, I or 2 nodal metastasis; $\mathrm{LN}+(>2)$, more than 2 nodal metastasis; $L N$, lymph node; $L S R$, long-to-short ratio.

pathology, with a high false-negative rate. US has a low sensitivity and cannot determine suspicious ALNs accurately in early breast cancer. As an important supplement to preoperative US, SLNB is an important means of accurate $\mathrm{N}$ staging. The present results do not support the hypothesis that preoperative US should be used instead of SLNB to detect ALN metastasis in early breast cancer.

Lee et al analyzed 224 patients, and the results showed that the false-negative rate of preoperative ultrasound for ALN involvement was higher, which was consistent with 

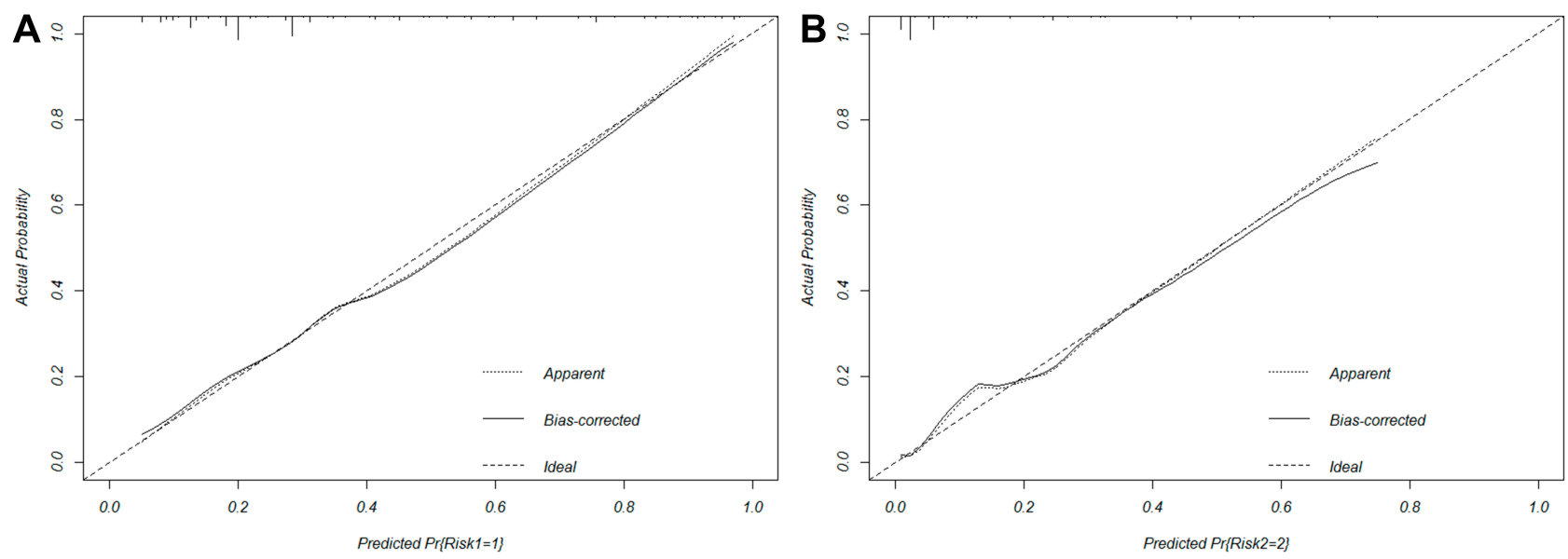

Figure 3 Calibration curve of the nomograms.

Notes: (A) the predictive model of RiskI ( $\mathrm{LN}-$ vs $\mathrm{LN}+$ ); (B) the predictive model of Risk2 (LN- and $\mathrm{LN}+[\mathrm{I}-2]$ vs $\mathrm{LN}+[>2])$.

Abbreviations: $L N-$, disease-free axillae; $L N+$, any nodal metastasis; $L N+(I-2)$, I or 2 nodal metastasis; $L N+(>2)$, more than 2 nodal metastasis.

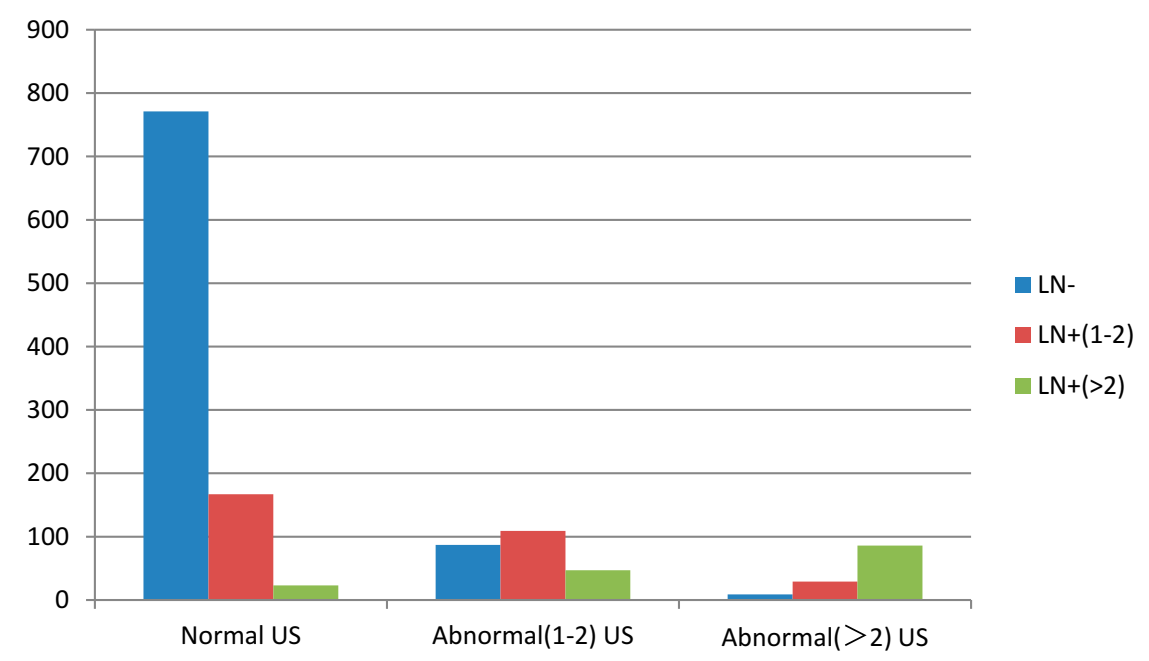

Figure 4 Distribution of patients with abnormal ALNs on US.

Abbreviations: $\mathrm{LN}-$, disease-free axillae; $\mathrm{LN}+(\mathrm{I}-2)$, I or 2 nodal metastasis; $\mathrm{LN}+(>2)$, more than 2 nodal metastasis.

our study results. ${ }^{22}$ SLNB is still needed in patients with negative preoperative US. Among patients with $>2$ suspicious ALNs on US, only $69.4 \%$ of the patients were pathologically confirmed as having a high axillary tumor burden, and the results of the study did not support direct ALND for such patients. Next, we need to explore the causes of false negative US from the perspective of clinicopathological and US characteristics to decrease missed diagnoses and misdiagnoses and improve the clinical application value of preoperative US in the optimization of surgical methods.

This study is a single-center retrospective study with heterogeneous study designs and limited populations. Thus, slight differences between the training group and the validation group should be interpreted with these limitations in mind. The ongoing Sentinel node vs Observation after axillary UltraSouND (SOUND) trial was designed to explore whether SLNB can be avoided when US is negative in early breast cancer. ${ }^{23}$ In this study, SLNB alone is not sufficient as a reference point for the involved LN number. In addition, cortical thickness was not specifically graded to be more effectively used in clinical diagnosis in this study.

\section{Conclusion}

Molecular subtype, LVI, mass descriptors (size, margin, microcalcification and blood flow signal) and LN descriptors (shape, cortical thickness and LSR) were independent 
influencing factors for ALN involvement in early breast cancer. The simple prediction models based on US features alone have a high accuracy in predicting the ALN metastasis rate and high tumor burden rate. Compared with the prediction model based on clinicopathological features combined with US features, it is more intuitive and accurate and can realize individual prediction; thus, it should be promoted.

\section{Disclosure}

The authors report no conflicts of interest in this work.

\section{References}

1. Giuliano AE, Ballman KV, McCall L, et al. Effect of axillary dissection vs no axillary dissection on 10-year overall survival among women with invasive breast cancer and sentinel node metastasis: the ACOSOG Z0011 (Alliance) randomized clinical trial. JAMA. 2017;318(10):918-926. doi:10.1001/jama.2017.11470

2. Dumitru D, Khan A, Catanuto G, Rocco N, Nava MB, Benson JR. Axillary surgery in breast cancer: the beginning of the end. Minerva Chir. 2018;73(3):314-321. doi:10.23736/s0026-4733.18.07728-3

3. Chen JY, Chen JJ, Yang BL, et al. Predicting sentinel lymph node metastasis in a Chinese breast cancer population: assessment of an existing nomogram and a new predictive nomogram. Breast Cancer Res Treat. 2012;135(3):839-848. doi:10.1007/s10549-012-2219-x

4. Huang J, Chen X, Fei X, et al. Risk factors of non-sentinel lymph node metastasis and performance of MSKCC nomogramin breast cancer patients with metastatic sentinel lymph node. Zhonghua Wai Ke Za Zhi. 2015;53 (12):941-946. doi:10.3760/cma.j.issn.0529-5815.2015.12.011

5. Chue KM, Yong WS, Thike AA, et al. Predicting the likelihood of additional lymph node metastasis in sentinel lymph node positive breast cancer: validation of the Memorial Sloan-Kettering Cancer Centre (MSKCC) nomogram. J Clin Pathol. 2014;67(2):112-119. doi:10.1136/jclinpath-2013-201524

6. Adler DD, Carson PL, Rubin JM, Quinn-reid D. Doppler ultrasound color flow imaging in the study of breast cancer: preliminary findings. Ultrasound Med Biol. 1990;16(6):553-559. doi:10.1016/03015629(90)90020-d

7. Net JM, Mirpuri TM, Plaza MJ, et al. Resident and fellow education feature: US evaluation of axillary lymph nodes. Radiographics. 2014;34(7):1817-1818. doi:10.1148/rg.347140081

8. Elmore LC, Appleton CM, Zhou G, Margenthaler JA. Axillary ultrasound in patients with clinically node-negative breast cancer: which features are predictive of disease? J Surg Res. 2013;184(1):234-240. doi:doi:10.1016/j.jss.2013.03.068

9. Hammond ME, Hayes DF, Dowsett M, et al. American Society of Clinical Oncology/College Of American Pathologists guideline recommendations for immunohistochemical testing of estrogen and progesterone receptors in breast cancer. J Clin Oncol. 2010;28(16):2784-2795. doi: $10.1200 /$ jco.2009.25.6529
10. Wolff AC, Hammond ME, Hicks DG, et al. Recommendations for human epidermal growth factor receptor 2 testing in breast cancer: American Society of Clinical Oncology/College of American Pathologists clinical practice guideline update. J Clin Oncol. 2013;31(31):3997-4013. doi:10.1200/jco.2013.50.9984

11. Gradishar WJ, Anderson BO, Balassanian R, et al. NCCN guidelines insights: breast cancer, version 1.2017. JNCCN. 2017;15(4):433-451. doi:10.6004/jncen.2017.0044

12. Yu X, Hao X, Wan J, Wang Y, Yu L, Liu B. Correlation between ultrasound appearance of small breast cancer and axillary lymph node metastasis. Ultrasound Med Biol. 2018;44(2):342-349. doi:10.1016/j. ultrasmedbio.2017.09.020

13. Stachs A, Thi AT, Dieterich M, et al. Assessment of ultrasound features predicting axillary nodal metastasis in breast cancer: the impact of cortical thickness. Ultrasound Int Open. 2015;1(1):E19E24. doi:10.1055/s-0035-1555872

14. Saffar B, Bennett M, Metcalf C, Burrows S. Retrospective preoperative assessment of the axillary lymph nodes in patients with breast cancer and literature review. Clin Radiol. 2015;70(9):954-959. doi:10.1016/j.crad.2015.04.019

15. Guo Q, Dong Z, Zhang L, et al. Ultrasound features of breast cancer for predicting axillary lymph node metastasis. $J$ Ultrasound Med. 2018;37(6):1354. doi:10.1002/jum.14469

16. Kim GR, Choi JS, Han BK, et al. Preoperative axillary US in early-stage breast cancer: potential to prevent unnecessary axillary lymph node dissection. Radiology. 2018;288(1):55-63. doi:10.1148/ radiol.2018171987

17. Li J, Ma W, Jiang X, et al. Development and validation of nomograms predictive of axillary nodal status to guide surgical decision-making in early-stage breast cancer. $J$ Cancer. 2019;10 (5):1263-1274. doi:10.7150/jca.32386

18. Zhang J, Li X, Huang R, et al. A nomogram to predict the probability of axillary lymph node metastasis in female patients with breast cancer in China: a nationwide, multicenter, 10-year epidemiological study. Oncotarget. 2017;8(21):35311-35325. doi:10.18632/oncotarget.13330

19. Dihge L, Bendahl PO, Ryden L. Nomograms for preoperative prediction of axillary nodal status in breast cancer. Br J Surg. 2017;104 (11):1494-1505. doi:10.1002/bjs.10583

20. Wang NN, Yang ZJ, Wang X, et al. A mathematical prediction model incorporating molecular subtype for risk of non-sentinel lymph node metastasis in sentinel lymph node-positive breast cancer patients: a retrospective analysis and nomogram development. Breast Cancer. 2018;25(6):629-638. doi:10.1007/s12282-018-0863-7

21. Xin L, Chen L, Zhang H, et al. Analysis of detecting value of ultrasound and the clinic-pathological features of axillary metastasis in breast cancer. Zhonghua Wai Ke Za Zhi. 2014;52(12):924-928. doi:10.3760/cma.j.issn.0529-5815.2014.12.011

22. Lee B, Lim AK, Krell J, et al. The efficacy of axillary ultrasound in the detection of nodal metastasis in breast cancer. AJR Am J Roentgenol. 2013;200(3):W314-W320. doi:10.2214/AJR.12.9032

23. Gentilini $\mathrm{O}$, Veronesi U. Abandoning sentinel lymph node biopsy in early breast cancer? A new trial in progress at the European Institute of Oncology of Milan (SOUND: sentinel node vs observation after axillary UltraSouND). Breast. 2012;21(5):678-681. doi:10.1016/j. breast.2012.06.013
Cancer Management and Research

Publish your work in this journal

Cancer Management and Research is an international, peer-reviewed open access journal focusing on cancer research and the optimal use of preventative and integrated treatment interventions to achieve improved outcomes, enhanced survival and quality of life for the cancer patient.
The manuscript management system is completely online and includes a very quick and fair peer-review system, which is all easy to use. Visit http://www.dovepress.com/testimonials.php to read real quotes from published authors. 